\title{
Transient Zebra-like Hyperpigmentation in a Healthy Newborn
}

\author{
Angéla Meszes $^{1} \cdot$ Csilla Korponyai $^{1} \cdot$ Hajnalka Orvos $^{2} \cdot$ Zsanett Csoma $^{1}$
}

Received: 31 July 2015 / Accepted: 21 October 2015 / Published online: 4 December 2015

(C) Dr. K C Chaudhuri Foundation 2015

The authors present here the case of a healthy neonate born with extensive zebra-like hyperpigmentation along the lines of Blaschko with unique resolution of symptoms [1-5]. The neonate was born after an uneventful pregnancy via cesarean section in the 38th gestational week. Her birth weight was $3220 \mathrm{~g}$ and Apgar score was $10 / 10$ at $1^{\prime}$. Short after birth, cutaneous examination revealed asymmetrically distributed, reticular hyperpigmentation composed of 1-3 mm reddish-brown, homogeneous macules forming whorls and streaks along the lines of Blaschko on the back, abdomen, chest, gluteal region, right shoulder and arm, and left thigh (Fig. 1a\&b). The skin appendages, including hair and nails, were normal. Her family history was negative for any pigmentation disorder. Physical, neurological and ultrasound examination showed an otherwise healthy baby. On the 4th day of life, considerable fading of the streaks was noticed, and the girl became totally symptom-free by the age of $3 \mathrm{wk}$; no inflammation or papular, vesicular or verrucous eruption was observed. In view of the rapid regression of the skin symptoms, histological examination was not performed. The follow-up at the age of 9 mo did not show any recurrence of the symptoms; the somatic, motoric and mental development of the infant was normal.

Angéla Meszes

meszesangela@gmail.com

1 Department of Dermatology and Allergology, University of Szeged, Korányi fasor 6, Szeged H-6720, Hungary

2 Department of Obstetrics and Gynecology, University of Szeged, Semmelweis utca 1., Szeged 6720, Hungary
Linear whorled and naevoid hypermelanosis (LWNHM) is an extremely rare, sporadic pigmentary disorder characterized by hyperpigmented swirls and streaks along the lines of Blaschko. Symptoms usually can be seen at birth or develop in the first 1-2 y of life, often progressing for 1-2 y before stabilization, or become less prominent and show minimal fading with age. The typical, linear and whorled hyperpigmented streaks follow the lines of Blaschko. Pigmentary lesions are not preceded by inflammatory events, vesiculobullous or verrucous stages. Somatic mosaicism leading to the proliferation and

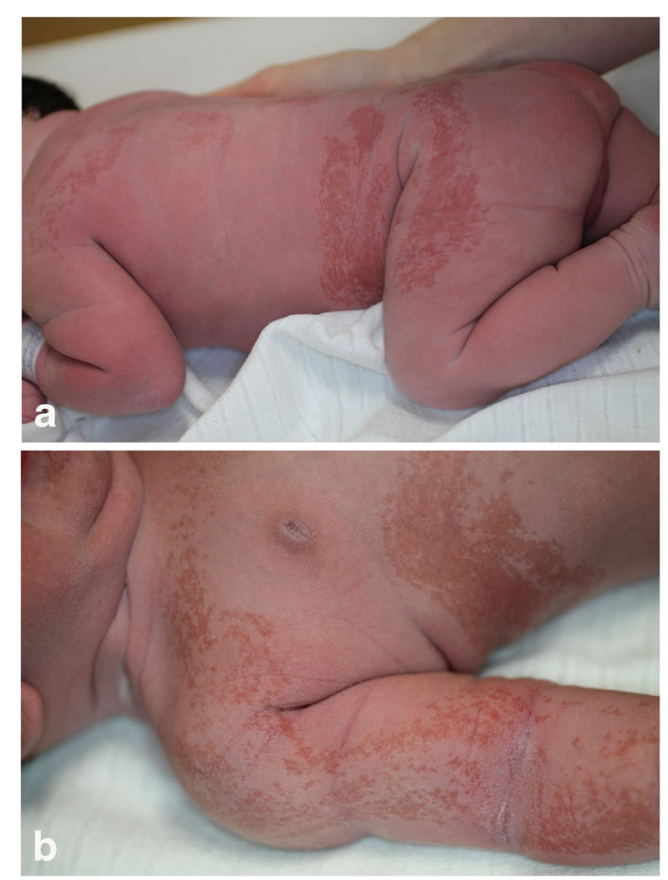

Fig. 1 a and b Extensive, asymmetrically distributed, reticular hyperpigmentation composed of 1-3 mm reddish-brown, homogeneous macules forming whorls and streaks along the lines of Blaschko on the 1st day of life 
migration of two or more melanocyte populations with different potentials for pigment production and distinct phenotypes, is the most likely cause of the disorder. The differential diagnosis includes stage III of incontinentia pigmenti, early stage of an epidermal naevus, $\mathrm{X}$-linked reticulate pigmentary disorder, Naegeli-Franceschetti-Jadassohn syndrome, or dermopathia pigmentosa reticularis.

Conflict of Interest None.

Source of Funding None.

\section{References}

1. Di Lernia V. Linear and whorled hypermelanosis. Pediatr Dermatol. 2007;24:205-10.

2. Harre J, Millikan LE. Linear and whorled pigmentation. Int $\mathbf{J}$ Dermatol. 1994;33:529-37.

3. Kalter DC, Griffiths WA, Atherton DJ. Linear and whorled nevoid hypermelanosis. J Am Acad Dermatol. 1988;19:1037-44.

4. Mehta V, Vasanth V, Balachandran C, Mathew M. Linear and whorled nevoid hypermelanosis. Int J Dermatol. 2011;50: 491-2.

5. Quecedo E, Febrer I, Aliaga A. Linear and whorled nevoid hypermelanosis. A spectrum of pigmentary disorders. Pediatr Dermatol. 1997;14:247-8. 